\title{
Membranas e barreiras para regeneração óssea guiada
}

\author{
Membranes and barriers for guided bone regeneration
}

\author{
Alan Dal'alba Pilger ${ }^{1}$, Luis Eduardo Schneider ${ }^{2 *}$, Gabrielle Mello da Silva ${ }^{3}$, Kalinka Crivellaro Crusius \\ Schneider ${ }^{4}$, Ricardo Smidt ${ }^{5}$
}

\begin{abstract}
${ }^{1}$ Graduado em Odontologia e Especialista em Prótese Dentária pela Universidade Luterana do Brasil, pela ULBRA/RS; ${ }^{2}$ Mestre em Cirurgia e Traumatologia Bucomaxilofacial, Doutor em Odontologia pela ULBRA, Professor Adjunto de Graduação em Odontologia da ULBRA; ${ }^{3}$ Graduada em Odontologia pela ULBRA; ${ }^{4}$ Mestre em Cirurgia e Traumatologia Bucomaxilofacial pela ULBRA; ${ }^{5}$ Doutor em Cirurgia e Traumatologia Bucomaxilofacial pela PUCRS, Professor Titular de Odontologia da ULBRA, RS
\end{abstract}

\begin{abstract}
Resumo
Introdução: a evolução das técnicas de reconstrução alveolar e dos biomateriais na regeneração óssea guiada (ROG), vêm trazendo consigo o desenvolvimento de novas membranas com diferentes características e propriedades. Objetivo: este trabalho tem como objetivo reunir dados das membranas utilizadas em procedimentos de ROG, presentes no mercado nacional, para facilitar ao clínico a escolha de um biomaterial que seja adequado ao procedimento planejado e com um desempenho favorável para a regeneração. Metodologia: foram incluídas 30 membranas para ROG registradas e regulamentadas pela Agência Nacional de Vigilância Sanitária (ANVISA). As empresas fabricantes foram contatadas para fornecer as informações dos seus respectivos produtos. Resultados: 30 membranas foram encontradas e tabuladas. Após a análise das informações obtidas pelos fabricantes, as mesmas foram classificadas nos seguintes itens: nome, empresa fabricante, origem, tempo de bioreabsorção, possibilidade de exposição ao meio bucal, diâmetro dos orifícios e apresentação. Discussão: as propriedades e características específicas de cada membrana podem determinar diferentes resultados, sendo importante para o profissional conhecer essas diferenças para selecionar os materiais mais indicados aos procedimentos de ROG de acordo com os objetivos de cada caso. Dessa forma, os resultados podem ser previsíveis e atender da melhor forma possível as expectativas do tratamento com embasamento científico. Conclusão: o presente estudo tabulou 30 membranas quanto as suas principais características, visando orientar os profissionais da saúde na seleção da membrana mais adequada para alcançar seus objetivos no tratamento da ROG.

Palavras-chave: Regeneração Óssea. Membranas Artificiais. Regeneração Tecidual Guiada.
\end{abstract}

\begin{abstract}
Introduction: the evolution of alveolar reconstruction techniques and biomaterials in guided bone regeneration (GBR), have brought with it the development of new membranes with different characteristics and properties. Objective: this study aims to gather data from the membranes used for ROG procedures present in the national market, to facilitate the clinician to choose a biomaterial that is suitable for the planned procedure and with a favorable performance for regeneration. Metodology: 30 membranes were included, registered and regulated by ANVISA. The manufacturing companies were contacted to provide information on their respective products. Results: 30 membranes were found and tabulated after analyzing the information obtained by the manufacturers, they were classified in the following items: name, manufacturer company, origin, time of resorption, possibility of exposure to the oral environment, diameter of the holes and presentation. Discussion: the specific properties and characteristics of each membrane can determine different results and, therefore, it is important for the professional to know these differences in order to select the most suitable materials for the GBR procedures according to the objectives of each case. In this way, the results can be predictable and best meet the expectations of the treatment with a correct scientific basis. Conclusion: the present study tabulated 30 membranes as to their main characteristics, aiming to guide health professionals in the selection of the most appropriate membrane to achieve their goals in the treatment of GBR.

Keywords: Bone Regeneration. Artificial Membranes. Guided Tissue Regeneration.
\end{abstract}

\section{INTRODUÇÃO}

Um adequado volume ósseo é um dos pré-requisitos para um tratamento previsível na reabilitação com implantes dentários. Contudo, em muitos casos, a presença de defeitos ósseos alveolares verticais e/ou horizontais acompanham a ausência dentária. A reconstrução dos

Correpondente/Corresponding: *Luis Eduardo Schneider - End: Rua Joaquim Nabuco, № 828, sala $N^{\circ} 1302$, Novo Hamburgo/RS - CEP: 93310-002 - Tel: (51) 3593-1835 - E-mail: leschneider0@gmail.comng defeitos ósseos alveolares permanece desafiadora apesar dos avanços em técnicas cirúrgicas e a disponibilidade de diferentes tipos de biomateriais. As técnicas tradicionalmente relatadas para a reconstrução alveolar incluem variações da regeneração óssea guiada (ROG) que compreendem a utilização de uma membrana que pode estar associada à utilização de biomateriais substitutos ósseos ${ }^{1}$, enxertos autógenos ou uma combinação desses. A ROG é relatada com os resultados mais previsíveis para preencher defeitos ósseos peri-implantares 
e fornecer estabilidade a longo prazo para as regiões regeneradas.

Para permitir o reparo ósseo com o procedimento de ROG, é necessária a utilização de uma barreira para estabilizar o coágulo e/ou biomaterial substituto ósseo, como também, evitar a invasão e migração de células epiteliais do tecido conjuntivo na área onde a angiogênese e a osteogênese devam ocorrer. As células dos tecidos bucais apresentam taxas de migração e velocidade diferentes para ocupar a área de cicatrização². A formação de tecido conjuntivo é mais rápida quando comparada a formação de tecido ósseo e assim, a membrana atua como uma barreira física que impede o crescimento do tecido conjuntivo na área do defeito ósseo. As células selecionadas são provenientes do osso circundante e desta forma, a regeneração óssea poderá ocorrer sem interferência de outros tipos de tecidos.

Para que o profissional determine qual membrana será utilizada no procedimento de ROG, é imperativo que conheça suas propriedades e comportamento nos tecidos bem como suas indicações. Este trabalho tem como objetivo reunir dados das membranas utilizadas para procedimentos de ROG presentes no mercado nacional, para facilitar ao clínico a escolha de um biomaterial que seja adequado ao procedimento planejado e com um desempenho favorável para a regeneração.

\section{REVISÃO DE LITERATURA}

As membranas que apresentam função de barreira, idealmente deveriam apresentar cinco principais critérios: biocompatibilidade, capacidade de manutenção de espaço, oclusividade celular, integridade estrutural e adequado gerenciamento clínico ${ }^{3}$.

\section{Biocompatibilidade}

A membrana deve fornecer um nível aceitável de biocompatibilidade. A interação entre o material e o tecido não deve afetar adversamente os tecidos circundantes para que a cicatrização pretendida seja alcançada e com segurança do paciente ${ }^{4}$. Entretanto a biocompatibilidade é um termo relativo pois praticamente nenhum material é completamente inerte ${ }^{5}$.

\section{Capacidade de manutenção de espaço}

A membrana deve possuir rigidez para criar e manter um espaço adequado para a regeneração óssea (para o crescimento e suporte tecidual), principalmente em grandes defeitos. Esse princípio está relacionado à espessura e rigidez da membrana. $O$ material também deve ser adequadamente maleável para fornecer a geometria específica necessária para a reconstrução funcional, mas também seja suficientemente rígido para suportar as pressões exercidas por forças externas como a mastigação ${ }^{6}$. Se a membrana entrar em colapso, o volume de regeneração é reduzido e o resultado clínico ideal pode não ser alcançado 4 .

\section{Oclusividade celular}

Uma barreira deve ser idealmente oclusiva para evitar formação de tecido fibroso através da invasão das células epiteliais, tecido conjuntivo ou fibroblastos e permitir a regeneração óssea. A oclusividade está relacionada à porosidade pois esse fator tem uma grande influência no potencial de invasão celular? ${ }^{7}$. Os poros de membrana facilitam a difusão de fluidos, oxigênio, nutrientes e substâncias bioativas para o crescimento celular, o que é vital para regeneração do tecido ósseo. A função barreira seleciona o tipo de células quando a membrana apresenta poros $<8 \mu \mathrm{m}$ e seus bordos estão perfeitamente adaptados ao tecido ósseo, desta forma a oclusividade celular será obtida. Um tamanho de poro grande permite que essas células de crescimento mais rápido superpovoem o espaço do defeito e inibam a infiltração e atividade de células formadoras de tecido ósseo ${ }^{6}$, além de atuarem como via para contaminação bacteriana do biomaterial substituto ósseo em caso de exposição da membrana. As propriedades das membranas para seleção celular e contaminação bacteriana estão expressas na figura 1.

\section{Integridade estrutural}

A integridade estrutural da membrana deve manter um perfil de bioreabsorção (quando bioreabsorvível) compatível com o período de neoformação do tecido ósseo e sua adaptação às bordas do defeito ósseo constituem pré-requisitos para a previsibilidade da $\mathrm{ROG}^{8}$. Essa adaptação depende da capacidade de manutenção do espaço e modelagem da membrana para a forma do defeito. Membranas muito rígidas podem apresentar dificuldade de adaptação em seus bordos.

\section{Gerenciamento clínico}

A membrana deve ser prática para uso clínico. Membranas muito maleáveis podem apresentar complicações na manutenção do espaço necessário para a ROG. Por outro lado, uma membrana muito rígida pode apresentar dificuldade ao ser moldada e a falta de adaptação de suas bordas, possivelmente afiadas, podem perfurar o tecido gengival e causar a subsequente exposição da mesma ${ }^{9}$.

As membranas podem ser basicamente classificadas em bioreabsorvíveis (para evitar uma segunda cirurgia de remoção da membrana) e não bioreabsorvíveis (que requerem um segundo procedimento cirúrgico de remoção da membrana).

A utilização das membranas junto aos tecidos bucais normalmente são bem toleradas e com poucas reações indesejadas, contudo, a exposição não intencional ao meio bucal, a contaminação bacteriana e a perda precoce da capacidade de seleção celular, são algumas das complicações comumente relatadas na literatura. Dessa forma, de acordo com os objetivos do tratamento, a correta seleção dos materiais utilizados deve ser realizada para potencializar resultados e minimizar os riscos de complicações. 
As membranas podem ser classificadas quanto ao seu comportamento biológico em membranas não bioreabsorvíeis e membranas bioreabsorvíveis. Devemos realizar a seleção de membranas não bioreabsorvíveis quando um segundo procedimento para a remoção da membrana está previsto ou na necessidade de manter a membrana exposta ao meio bucal intencionalmente. Em caso de exposição intencional da membrana, esta deve ter a função de barreira para contaminação bacteriana, com ausência de poros ou porosidade de até $0,3 \mu \mathrm{m}$. As membranas bioreabsorvíveis devem ser selecionadas quando um segundo procedimento de sua remoção não está previsto e de acordo com o tempo de bioreabsorção, adequado ao objetivo do tratamento.

\section{Membranas não bioreabsorvíveis}

As membranas não bioreabsorvíeis podem ter como origem o politetrafluoretileno expandido (e-PTFE), politetrafluoretileno denso (d-PTFE), titânio, e-PTFE reforçada com titânio e de polipropileno $0^{10,11}$.

\section{Politetrafluoretileno expandido (e-PTFE)}

As membranas de politetrafluoretileno expandido são originárias de um polímero inerte biologicamente e quimicamente estável. Possuem estrutura porosa e forma flexível. Mostram resistência à degradação microbiológica e enzimática, além de não estimularem reações imunológicas. Quanto à porosidade, consistem em duas superfícies diferentes: uma microestrutural (porosidade de 100 a $300 \mu \mathrm{m}$ ) e uma parte oclusiva (porosidade $<8$ $\mu \mathrm{m})$. A microestrutura promove adesão tecidual em sua superfície, o que melhora a estabilidade da membrana e permite a difusão de nutrientes através dos poros. A porção oclusiva, pelo contrário é relativamente impermeável a fluidos e bloqueia a migração de células de tecidos moles na área de crescimento ósseo ${ }^{11}$.

\section{Politetrafluoretileno denso (d-PTFE)}

As membranas de d-PTFE são produzidas com uma forma menos porosa de politetrafluoretileno, mantendo o comportamento inerte e estável. A baixa porosidade $(<0,3 \mu \mathrm{m})$ impede a adesão celular e torna a membrana menos propensa à incorporação de bactérias em sua estrutura ${ }^{10}$. Portanto, podem ser intencionalmente expostas ao meio bucal. Superfícies porosas favorecem o acúmulo de biofilme bacteriano especificamente se a superfície tiver entre 10 a $100 \mu \mathrm{m}^{12}$.

\section{Malhas de titânio}

A malha de titânio apresenta capacidade de manutenção do espaço com um maior grau de previsibilidade em casos de grandes defeitos ósseos ${ }^{3,9}$. A baixa densidade de titânio fornece um material leve, de alta resistência estrutural e resistente à corrosão. Devido a plasticidade, pode ser dobrada em diferentes formas para ajustar o contorno da crista alveolar durante a cirurgia ${ }^{13}$, cobrindo defeitos alveolares e mantendo a forma desejada da crista alveolar podendo ser efetivas para prevenir o colapso de tecidos moles e partículas ósseas durante a regeneração. O corte e adaptação da malha no defeito ósseo pode gerar bordas afiadas que podem ser responsáveis pela exposição da mesma ${ }^{9}$. A rigidez também causa um aumento no número de exposições por irritação nos retaIhos cirúrgicos. A presença de poros nas malhas de titânio permitem um suprimento vascular adequado aos tecidos subjacentes. Por esse motivo, quando expostas ao meio bucal devem ser avaliadas quanto à necessidade de sua remoção. Quanto à porosidade, podem ser classificadas em macroporosas e microporosas. Malhas de titânio microporosas possuem em média poros de $188 \mu \mathrm{m}$ e malhas macroporosas em média 300 a $400 \mu \mathrm{m}^{14}$. Desta forma, sua utilização está relacionada à estabilização do biomaterial substituto ósseo e enxertos de tecido ósseo, não apresentando função de barreira para seleção celular e não impedindo a contaminação bacteriana da área reconstruída em caso de exposição. Para oferecer seleção celular e proteção quanto a contaminação bacteriana, a malha de titânico não deve apresentar poros ou sua porosidade deve ser $<0,3 \mu \mathrm{m}$. O período médio de cicatrização decorrido para remoção das malhas de titânio quando sua função é estabilização mecânica da área reconstruída é de aproximadamente 7 meses, podendo variar entre um longo protocolo de espera ( 8 a 9 meses) e um curto ( 3 a 4 meses), dependendo do biomaterial substituto ósseo utilizado e a região (maxila ou mandíbula) ${ }^{15}$.

\section{E-PTFE reforçadas com titânio (Ti-e-PTFE)}

Quanto à utilização das membranas de e-PTFE reforçadas com titânio (Ti-e-PTFE), alguns pesquisadores apoiam sua eficácia, entretanto outros relatam que não apresentam vantagens adicionais na sua aplicação. No entanto, em defeitos maiores, a utilização do politetrafluoroetileno associado a um reforço de titânio na membrana pode ser vantajoso devido o aumento da estabilidade estrutural $^{16}$.

\section{Polipropileno}

O polipropileno é um material termoplástico fabricado polimerizando moléculas de propileno (derivado de petróleo). É flexível para moldagem, apresenta pouca densidade e uma excelente resistência química ${ }^{17}$. Não apresenta porosidade, agindo como barreira ao impedir a passagem de células de tecido conjuntivo e mantendo a região protegida para a regeneração do tecido ósseo. Apresenta impermeabilidade e pode ser utilizada sem a fixação com parafusos. Sua remoção é preconizada entre 7 a 10 dias após o procedimento reconstrutivo. A membrana de polipropileno quando utilizada intencionalmente exposta ao meio bucal, demonstrou viabilidade no processo de ROG $^{18}$. 


\section{Membranas bioreabsorvíveis}

As membranas bioreabsorvíveis foram introduzidas na tentativa de evitar uma segunda cirurgia necessária para remoção ${ }^{5}$. Por essa razão, membranas bioreabsorvíveis atraem tanto o clínico quanto os pacientes por reduzir a morbidade e dano tecidual. São originadas de grupos de po-

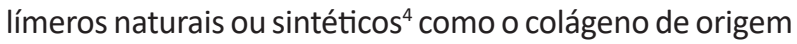
bovina e suína (naturais) e copolímeros de ácido polilático e poliglicólico (sintéticos). Essa variedade de fontes e de disponibilidade de materiais permitem a criação de diferentes membranas com diferentes propriedades físicas, químicas e mecânicas ${ }^{19}$, além de propriedades biológicas como biocompatibilidade e biodegradabilidade. Esses materiais são biocompatíveis, mas por definição não são inertes, uma vez que se espera alguma reação tecidual durante a sua degradação. As membranas são reabsorvidas pela atividade enzimática de macrófagos e leucócitos polimorfonucleares. Sofrem hidrólise e são eliminados do organismo pelo ciclo de Krebs como dióxido de carbono e água ${ }^{5}$.

Quando utilizadas em associação à técnica de ROG, foram relatadas aumento na regeneração óssea e redução da reabsorção do biomaterial substituto ósseo empregado. Kim et al. ${ }^{20}$ analisaram através de tomografia computadorizada a eficácia das membranas de colágeno em procedimentos de ROG, foi avaliado a quantidade e a qualidade óssea através da densidade óssea e das unidades de Hounsfield. Os resultados mostraram que as membranas de colágeno foram efetivas.

Algumas características esperadas incluem boa compatibilidade com os tecidos, oclusividade celular, barreira física, além de facilidade na aplicação e propriedades integrativas ${ }^{21}$.

De acordo com Adeyemo et al. ${ }^{22}$, a manutenção do volume de biomaterial substituto ósseo depende da estabilidade da membrana durante o processo de cicatrização. Uma reabsorção óssea significativa pode ocorrer em decorrência da instabilidade da membrana, dessa forma, seu colapso durante a cicatrização pode limitar ou eliminar a possibilidade de regeneração óssea ${ }^{23}$ e sua característica física macia pode prejudicar a estabilidade da membrana frente a pressão ou compressão. A atividade muscular na boca preocupa e limita o espaço para a ROG ${ }^{24}$, desta forma, podem ser utilizados dispositivos de fixação para auxiliar na estabilização da membrana. A degradação da membrana de colágeno pode ser alterada aumentando sua integridade estrutural através da reticulação (interligações poliméricas para aumentar a rigidez). Membranas derivadas de colágeno bovino ou suíno tipo I e tipo III geralmente apresentam maior grau de reticulação, permanecendo intactas por um período maior ou prolongando a biodegradação. Essa característica pode permitir uma melhor regeneração em defeitos ósseos maiores ${ }^{25}$.

Figura 1 - Organograma para seleção da membrana quanto ao comportamento bioabsorvível ou não bioabsorvível, como barreira para seleção celular e barreira para contaminação bacteriana.

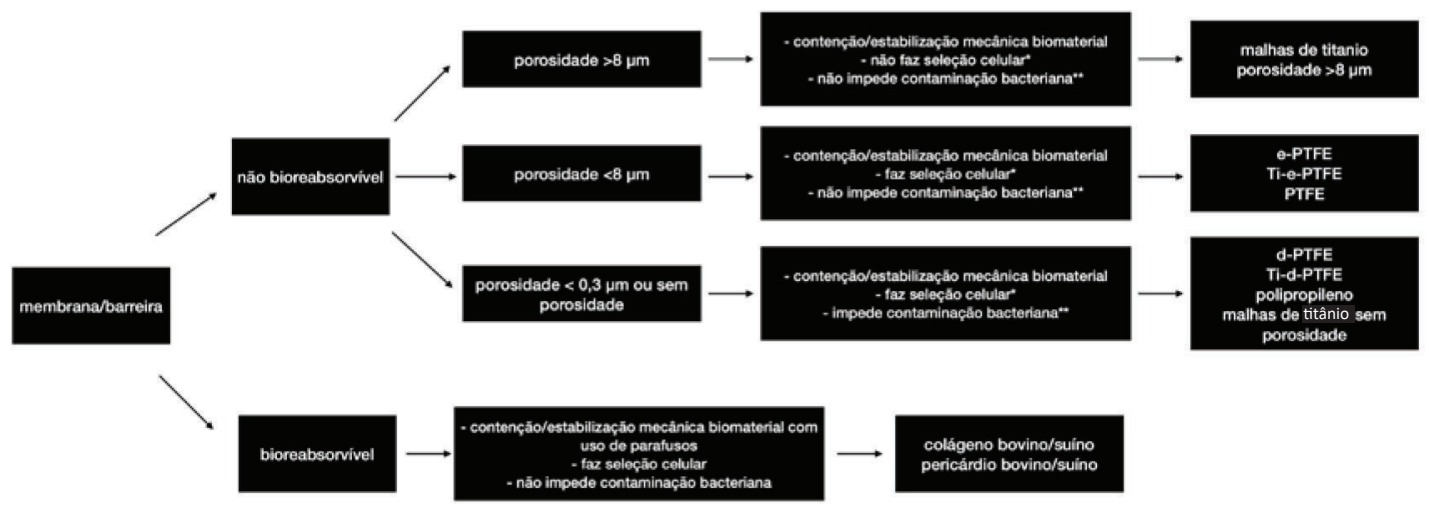

Fonte: Autoria própria

\section{METODOLOGIA}

Foram incluídos no presente estudo 30 membranas para serem utilizadas em procedimentos de ROG presentes no mercado nacional (Brasil), registradas e regulamentadas pela Agência Nacional de Vigilância Sanitária (ANVISA). As empresas fabricantes foram contatadas e consultadas para fornecerem as informações referentes aos seus produtos. Parte dos dados foram coletados nos sites que as empresas disponibilizam com conteúdo informativo aos cirurgiões-dentistas sobre seus respectivos produtos.

As informações coletadas a respeito dos biomateriais incluíram: nome do produto, empresa fabricante, origem, 
tempo de bioreabsorção, possibilidade de exposição ao meio bucal, diâmetro dos orifícios e apresentação. Os dados foram distribuídos em dois grupos conforme a classificação de membranas em bioreabsorvíveis e não bioreabsorvíveis.

Os artigos para o estudo foram selecionados por meio de buscas eletrônicas em bases de dados sem restrição de idiomas. Como ferramenta para a busca precisa dos artigos, foram utilizados descritores correspondentes ao estudo indexados no DECS (descritores em ciências da saúde): Regeneração Óssea, Membranas artificiais, Regeneração tecidual guiada.

\section{RESULTADOS}

As informações obtidas segundo os fabricantes de membranas com indicação para procedimentos de ROG disponíveis no mercado nacional estão expressas de maneira classificada na tabela 1 e tabela 2 .

As membranas foram organizadas conforme nome comercial e empresa. Foram classificadas em:

Origem: referência a matéria prima de onde provém a membrana.

Apresentação: aspecto no que diz respeito ao tamanho ou proporções físicas.

Tempo de bioreabsorção: tempo médio de bioreabsorção do material fornecido pelas empresas baseadas em estudo in vitro ou in vivo.

Orifícios: poros presentes na superfície das membranas medidas em micrômetros.

Tabela 1 - Classificação das membranas bioreabsorvíveis

\begin{tabular}{|c|c|c|c|}
\hline Nome e Empresa & Origem & $\begin{array}{c}\text { Tempo de } \\
\text { Bioreabsorção } \\
\text { (semanas) }\end{array}$ & Apresentação (mm) \\
\hline BioMend $^{\circledR}$ (Zimmer) & Colágeno Bovino & $\sim 8$ & $15 \times 20 ; 20 \times 30 ; 30 \times 40$ \\
\hline BioMend Extend ${ }^{\circledR}$ (Zimmer) & Colágeno Bovino & $\sim 18$ & $15 \times 20 ; 20 \times 30 ; 30 \times 40$ \\
\hline CollaTape ${ }^{\circledR}$ (Zimmer) & Colágeno Bovino & 2 & $1 \times 25 \times 75$ \\
\hline CollaCote ${ }^{\circledR}$ (Zimmer) & Colágeno Bovino & 2 & $3 \times 20 \times 40$ \\
\hline Collprotect $^{\circledR}$ (Straumann) & Colágeno Suíno & $8-12$ & $0,4 \times 15 \times 20 ; 0,4 \times 20 \times 30 ; 0,4 \times 30 \times 40$ \\
\hline CopiOs Pericardium ${ }^{\circledR}$ (Zimmer) & Pericárdio Bovino & $\sim 24$ & $15 \times 20 ; 20 \times 30 ; 30 \times 40$ \\
\hline Lumina-Coat ${ }^{\circledR}$ (Critéria Biomateriais) & Colágeno Bovino & $\sim 4-6$ & $1 \times 20 \times 30$ \\
\hline Lumina-Coat Double Time ${ }^{\circledR}$ (Critéria Biomateriais) & Colágeno Bovino & $\sim 8-10$ & $2 \times 20 \times 30$ \\
\hline Geistlich Bio-Gide ${ }^{\circledR}$ (Geistlich Pharma) & Colágeno Suíno & 2 & $13 \times 25 ; 25 \times 25 ; 30 \times 40$ \\
\hline Geistlich Bio-Gide Compressed ${ }^{\circledR}$ (Geistlich Pharma) & Colágeno Suíno & 2 & $13 \times 25 ; 20 \times 30$ \\
\hline Geistlich Bio-Gide Perio ${ }^{\circledR}$ (Geistlich Pharma) & Colágeno Suíno & 2 & $16 \times 22$ \\
\hline Geistlich Bio-Gide Shape ${ }^{\circledR}$ (Geistlich Pharma) & Colágeno Suíno & 2 & $14 \times 24$ \\
\hline GenDerm ${ }^{\circledR}$ (Baumer) & Colágeno Bovino & 6 & $20 \times 20 ; 30 \times 30$ \\
\hline GenDerm Flex ${ }^{\circledR}$ (Baumer) & Colágeno Bovino & 8 & $20 \times 20 ; 30 \times 30$ \\
\hline Jason ${ }^{\circledR}$ (Botiss Dental) & Pericárdio Suíno & $\sim 12-28$ & $15 \times 20 ; 20 \times 30 ; 30 \times 40$ \\
\hline OsseoGuard ${ }^{\circledR}$ (Biomet 3i) & Colágeno Bovino & $\sim 42-63$ & $15 \times 20 ; 20 \times 30 ; 30 \times 40$ \\
\hline OsseoGuard flex ${ }^{\circledR}$ (Biomet 3i) & Colágeno Bovino & $\sim 42-63$ & $15 \times 20 ; 20 \times 30 ; 30 \times 40$ \\
\hline Socket Repair ${ }^{\circledR}$ (Zimmer) & Colágeno Bovino & $\sim 26-30$ & $10 \times 20$ \\
\hline Surgidry ${ }^{\circledR}$ (Dental Membrana) & Colágeno Bovino & 4 & $20 \times 20 ; 20 \times 30 ; 30 \times 50$ \\
\hline
\end{tabular}

Fonte: Autoria própria 
Tabela 2 - Classificação das membranas não bioreabsorvíveis

\begin{tabular}{|c|c|c|c|c|}
\hline Nome e Empresa & Origem & Apresentação & $\begin{array}{c}\text { Orifícios } \\
\mu\end{array}$ & $\begin{array}{c}\text { Exposição ao } \\
\text { meio bucal }\end{array}$ \\
\hline Bone-Heal ${ }^{\circledast}$ & Polipropileno & $0,1 \times 30 \times 40 \mathrm{~mm}$ & - & Sim \\
\hline Cytoplast $^{\circledast}$ (Osteogenics Biomedical) & d-PTFE & $0,3 \times 24 \mathrm{~mm} \times 12 \mathrm{~mm} ; 0,3 \times 30 \mathrm{~mm} \times 25 \mathrm{~mm}$ & 0,3 & Sim \\
\hline $\begin{array}{l}\text { Cytoplasttm txt-200 }{ }^{\circledast} \text { (Osteogenics } \\
\text { Biomedical) }\end{array}$ & $\begin{array}{l}\text { d-PTFE com reforço de } \\
\text { titânio }\end{array}$ & $\begin{array}{l}0,3 \times 17 \mathrm{~mm} \times 25 \mathrm{~mm} ; 0,3 \times 20 \mathrm{~mm} \times 25 \mathrm{~mm} ; \\
0,3 \times 25 \mathrm{~mm} \times 30 \mathrm{~mm} ; 0,3 \times 30 \mathrm{~mm} \times 40 \mathrm{~mm}\end{array}$ & 0,3 & Sim \\
\hline Lumina PTFE $^{\circledR}$ (Critéria Biomateriais) & d-PTFE & $1 \times 20 \times 30 \mathrm{~mm}$ & - & Sim \\
\hline $\begin{array}{l}\text { Lumina-Grid Micro Mesh }{ }^{\circledR} \text { (Critéria } \\
\text { Biomateriais) }\end{array}$ & Titânio & $0,08 \times 20 \times 30 \mathrm{~mm}$ & 500 & Não \\
\hline $\begin{array}{l}\text { Lumina-Grid }{ }^{\circledR} \text { Macro Mesh (Critéria } \\
\text { Biomateriais) }\end{array}$ & Titânio & $0,08 \times 20 \times 30 \mathrm{~mm}$ & 1500 & Não \\
\hline $\begin{array}{l}\text { Surgitime } \text { ePTFE}^{\circledR} \text { (Bionnovation Bio- } \\
\text { medical) }\end{array}$ & e-PTFE & $0,25 \times 12 \times 24 \mathrm{~mm} ; 0,25 \times 30 \times 20 \mathrm{~mm}$ & 2,0 & Não \\
\hline $\begin{array}{l}\text { Surgitime } \text { PTFE }^{\circledR} \text { (Bionnovation Bio- } \\
\text { medical) }\end{array}$ & PTFE & $\begin{array}{l}0,1 \times 30 \times 20 \mathrm{~mm} \\
0,25 \times 30 \times 20 \mathrm{~mm}\end{array}$ & 2,0 & Não \\
\hline $\begin{array}{l}\text { Surgitime Titânio }{ }^{\circledR} \text { (Bionnovation Bio- } \\
\text { medical) }\end{array}$ & Titânio & $0,04 \times 34 \times 25 \mathrm{~mm} ; 0,08 \times 34 \times 25 \mathrm{~mm}$ & 150 & Não \\
\hline $\begin{array}{l}\text { Surgitime Titânio Seal }{ }^{\circledR} \text { (Bionnovation } \\
\text { Biomedical) }\end{array}$ & Titânio & $0,04 \times 34 \times 25 \mathrm{~mm}$ & - & Sim \\
\hline Ti Mesh Lock - Intra-Lock ${ }^{\circledR}$ (Mesh Lock) & Titânio & $0,15 \times 40 \mathrm{~mm} \times 60 \mathrm{~mm}$ & 800 & Não \\
\hline
\end{tabular}

Fonte: Autoria própria

\section{DISCUSSÃO}

Tanto as membranas bioreabsorvíveis como as não bioreabsorvíveis têm eficácia clínica comprovada na técnica de ROG, apresentando vantagens e desvantagens respectivamente ${ }^{26}$.

Contudo, ambas devem apresentar biocompatibilidade e proporcionar oclusividade celular para evitar a invasão de tecido mole, contaminação bacteriana e a ocorrência de infecção. Estudos relataram que a membrana utilizada em ROG deve manter sua função de barreira até a matriz provisória e o osso reticular estarem presentes. A função de barreira significa que a oclusividade deve ser mantida pelo menos até que ocorra a cicatrização do tecido mole. Devendo ser adequada às demandas clínicas de cada caso e esse processo normalmente leva cerca de 2 semanas $^{27}$. O uso de membranas em procedimentos de ROG foram relatados em uma revisão sistemática e de meta análise com a capacidade de diminuir a proliferação de tecido não mineralizado, o que favorece a estabilização dos implantes dentários ${ }^{28}$. Bartee, em 2001 descreveu um protocolo cirúrgico padronizado utilizando membranas de d-PTFE e substitutos ósseos para preservação alveolar e/ou implantes imediatos. Essa técnica é baseada na remoção de membrana aos 21-28 dias após a cirurgia ${ }^{29}$. No entanto, existem controvérsias sobre o momento ideal para a remoção da membrana, que variam de 3 a 6 semanas $^{30}$.

Rasmusson et $a l .{ }^{31}$, relataram que as membranas são efetivas enquanto permanecem em posição. $O$ deslocamento da membrana, seja do tipo não bioreabsorvível ou bioreabsorvível pode influenciar no resultado da ROG. Esse deslocamento pode ocorrer durante a realização da sutura ou posteriormente por ação mastigatória e ou pressão/movimentação dos tecidos bucais. Foram relatadas porcentagens maiores de falhas de implantes instalados em sítios de ROG sem utilização de membranas além de porcentagens de osso neoformado menores quando não foram utilizadas membranas para técnicas de ROG como elevação do seio maxilar ${ }^{32}$. A presença de uma superfície porosa na membrana é relatada como um fator importante para alcançar resultados satisfatórios na terapia regenerativa pois favorece a estabilidade da membrana e difusão de nutrientes ${ }^{8}$. Taxas significativas de regeneração óssea foram observadas no período inicial de cicatrização utilizando membranas porosas. No entanto, após 12 semanas de cicatrização, em estudo também utilizando membranas não porosas, quantidades semelhantes de osso regenerado foram observados ${ }^{33}$. Independente 
da membrana escolhida, sua estabilidade é um fator fundamental para o sucesso da ROG. Essa estabilidade pode ser obtida com auxílio de parafusos de fixação visando reduzir micromovimentos ${ }^{34}$.

A exposição da membrana é um fator de risco presente e que deve ser levada em consideração quando a ROG é associada a uma membrana não bioreabsorvíve ${ }^{35}$. Essa exposição que ocorre de maneira espontânea ao ambiente bucal é acompanhada por colonização bacteriana provocando resultados regenerativos menos favoráveis ${ }^{36}$ ou insuficientes. Quando uma membrana bioreabsorvível fica exposta, há degradação acelerada da estrutura de colágeno da membrana, levando a uma função de barreira reduzida, podendo comprometer os resultados da regeneração óssea ${ }^{27}$.

Foram relatada altas taxas de exposição espontânea das membranas e-PTFE. Para o tratamento dessas complicações, foi sugerida a remoção da membrana devido a colonização bacteriana e subsequente infecção $0^{37}$. Após sua remoção, dependendo do tempo em que a membrana permaneceu efetiva, pode ocorrer considerável reabsorção do biomaterial substituto ósseo, o que diminui os resultados da cirurgia regenerativa. No entanto, em alguns casos de exposição da membrana, não há necessidade urgente de removê-la, sua estrutura porosa pode permitir uma vascularização nos tecidos mais profundos e um controle químico de placa pode ser utilizado para controle da contaminação ${ }^{15}$.

Novas membranas vêm sendo estudadas para a capacidade de suportar a cicatrização gengival mesmo após a exposição prematura na cavidade buca ${ }^{38}$. Essas membranas consistem em uma estrutura com colágeno reticulado com um metabólito nativo que garante a integridade funcional por seis meses em membranas não expostas. Essa tecnologia de reticulação torna a membrana capaz de suportar a degradação colagenolítica bacteriana mesmo quando exposta prematuramente, permitindo a cicatrização de tecidos moles sobre as membranas expostas ${ }^{26}$. Um estudo retrospectivo publicado recentemente concluiu que a cobertura da membrana diminui o deslocamento pós-operatório do biomaterial e evita que partículas do substituto ósseo penetrem na mucosa bucal ${ }^{39}$.

A instrução de higiene bucal deve ser elaborada de acordo com as necessidades individuais dos pacientes e suas habilidades manuais ${ }^{1}$. As consultas subsequentes de revisão devem considerar reforços na instrução aos pacientes quanto à higiene bucal e motivação para realizá-la. As condições da mucosa são avaliadas visualmente e por palpação. Presença de eritema, hiperplasia, supuração, inchaço e/ou dor à palpação são sinais e sintomas considerados mais graves, sendo que essas complicações se mostraram mais significativas em pacientes que utilizaram próteses removíveis provisórias em vez de próteses provisórias fixas ${ }^{1}$. Zitzmann, Schärer, Marinello ${ }^{1}$, observaram que existe uma forte associação entre a presença de placa e a ocorrência de complicações. Verificou-se que os locais que apresentavam placa eram 7,74 vezes mais propensos a problemas na mucosa que aqueles sem placa $\mathrm{P}<.0001$. Para o controle e maior previsibilidade do procedimento, é normalmente utilizado uma profilaxia antibiótica pré-operatória e controle químico da higiene bucal com solução de Clorexidina $0,12 \%$ duas vezes ao dia por 10 dias $^{40}$.

\section{CONCLUSÃO}

A estabilidade da membrana deve ser mantida durante a regeneração óssea independente de qual membrana for utilizada. Resultados promissores e com menores taxas de complicação vêm sendo alcançados com membranas de colágeno. É muito difícil comparar as membranas apenas usando as informações relatadas pelos fabricantes devido a falta de uniformidade das informações disponíveis referente as diferentes condições de processamento, tamanhos e propriedades, o que torna difícil comparar os resultados clínicos de sua aplicação. Este estudo tabulou as membranas utilizadas em procedimentos de ROG, quanto suas principais características biológicas, visando orientar os profissionais da saúde na escolha da membrana e ou barreira mais adequada para alcançar seus objetivos no tratamento.

\section{REFERÊNCIAS}

1. ZITZMANN, N. U.; SCHÄRER, P.; MARINELLO, C. P. Long-term results of implants treated with guided bone regeneration: a 5-year prospective study. Int. J. Oral Maxillofac. Implants, Chicago. v. 16, n. 3, 2001.

2. DAHLIN, C. et al. Healing of bone defects by guided tissue regeneration. Plast. Reconst. Surg., Oklahoma City. v. 81, n. 5, p. 672-676, 1988.

3. SCANTLEBURY, T. V. 1982-1992: A decade of technology development for guided tissue regeneration. J. Periodontol., Chicago. v. 64, p. 1129-1137, 1993.

4. RAKHMATIA, Y. D. et al. Current barrier membranes: titanium mesh and other membranes for guided bone regeneration in dental applications. J. Prosthodontic Res., lowa City. v. 57, n. 1, p. 3-14, 2013.

5. LANG, N. P.; Lindhe, J. Tratado de periodontia clínica e implantologia oral. Rio de Janeiro: Guanabara Koogan, 2018. v. 6. p. 871.

6. HEINZE, J. A space-maintaining resorbable membrane for guided tissue regeneration. In: Annual conference of the International Association of Dental Research. Honolulu. 2004.

7. SALZMANN, D. L. et al. The effects of porosity on endothelialization of ePTFE implanted in subcutaneous and adipose tissue. J. Biomed. Mater Res., Hoboken. v. 34, n. 4, p. 463-476, 1997.

8. KOSTOPOULOS, L.; KARRING, T. Augmentation of the rat mandible using guided tissue regeneration. Clin. Oral Implants Res., Copenhagen. v. 5, n. 2, p. 75-82, 1994.

9. BECKER, W. et al. A prospective multi-center study evaluating periodontal regeneration for Class II furcation invasions and intrabony defects after treatment with a bioabsorbable barrier membrane: 1-year results. J. Periodontol., Indianapolis. v. 67, n. 7, p. 641-649, 1996.

10. BARBOZA, E. P. et al. Guided bone regeneration using nonexpanded polytetrafluoroethylene membranes in preparation for dental implant placements - a report of 420 cases. Implant Dent., Baltimore. v. 19, n. 1, p. 2-7, 2010

11. RONDA, M. et al. Expanded vs. dense polytetrafluoroethylene 
membranes in vertical ridge augmentation around dental implants: a prospective randomized controlled clinical trial. Clin. Oral Implants Res., Copenhagen. v. 25, n. 7, p. 859-866, 2014.

12. MERRILL, E. W. Distinctions and correspondences among surfaces contacting blood. Ann. N. Y. Acad. Sci., Copenhagen. v. 516, n. 1, p. 196-203, 1987.

13. HER, S.; KANG, T.; FIEN, M. J. Titanium mesh as an alternative to a membrane for ridge augmentation. J. Oral Maxillofac. Surg., Philadelphia. v. 70, n. 4, p. 803-810, 2012.

14. GUTTA, R. et al. Barrier membranes used for ridge augmentation: is there an optimal pore size?. J. Oral Maxillofac. Surg., Philadelphia v. 67, n. 6, p. 1218-1225, 2009.

15. DAL POLO, M. R. et al. Alveolar ridge reconstruction with titanium meshes: a systematic review of the literature. Med. Oral Patol. Oral Cir. Bucal, Valencia. v. 19, n. 6, p. e639, 2014.

16. RETZEPI, M. A. R. I.; DONOS, N. Guided bone regeneration: biological principle and therapeutic applications. Clin. Oral Implants Res., Copenhagen. v. 21, n. 6, p. 567-576, 2010.

17. MADDAH, H. A. Polypropylene as a promising plastic: a review. American Journal of Polymer Science, Los Angeles. v. 6, n. 1, p. 1-11, 2016.

18. SALOMÃO, M.; JTT, S. Regeneração óssea guiada através de barreira exposta ao meio bucal após exodontias. Relato de caso. Rev. Bras. Implantodont. Protese Implant., Curitiba. v. 7, n. 10, p. 5-7, 2010.

19. FIELDS, T. Guided bone regeneration: focus on resorbable membranes. In: Baylor oral surgery Thursday morning conference. 2001.

20. KIM, M. et al. Effect of bone mineral with or without collagen membrane in ridge dehiscence defects following premolar extraction. In vivo, Athens. v. 22, n. 2, p. 231-236, 2008.

21. GHANAATI, S.. Non-cross-linked porcine-based collagen I-III membranes do not require high vascularization rates for their integration within the implantation bed: A paradigm shift. Acta biomaterialia, Oxford. v. 8, n. 8, p. 3061-3072, 2012.

22. ADEYEMO, W. L. et al. Healing of onlay mandibular bone grafts covered with collagen membrane or bovine bone substitutes: a microscopical and immunohistochemical study in the sheep. Int. J. Oral Maxillofac. Surg., Philadelphia, v. 37, n. 7, p. 651-659, 2008.

23. DAHLIN, C.; ALBERIUS, P.; LINDE, A. Osteopromotion for cranioplasty: An experimental study in rats using a membrane technique. J. Neurosurg., Baltimore. v. 74, n. 3, p. 487-491, 1991.

24. LI, H. et al. Experiment of GBR for repair of peri-implant alveolar defects in beagle dogs. Sci. Rep., v. 8, n. 1, p. 1-7, 2018.

25. TAL, H. et al. Long-term bio-degradation of cross-linked and noncross-linked collagen barriers in human guided bone regeneration. Clin. Oral Implants Res., Copenhagen. v. 19, n. 3, p. 295-302, 2008.

26. MOSES, O. et al. Healing of dehiscence-type defects in implants placed together with different barrier membranes: a comparative clinical study. Clinical oral implants research, Copenhagen. v. 16, n. 2, p. 210-219, 2005.

27. ZITZMANN, N. U.; NAEF, R.; SCHÄRER, P. Resorbable versus nonresorbable membranes in combination with Bio-Oss for guided bone regeneration. Int. J. Oral Maxillofac. Implants, Lombard, v. 12, n. 6, 1997.

28. STARCH-JENSEN, T. et al. Maxillary Sinus Floor Augmentation With or Without Barrier Membrane Coverage of the Lateral Window: a Systematic Review and Meta-Analysis. J. Oral Maxillofac. Res., [s.I], v. 10, n. 4, 2019.

29. BARTEE, B. K. A simplified technique for ridge preservation after tooth extraction. Dentist. today, Montclair. v. 14, n. 10, p. 62-67, 1995.

30. CARBONELL, J. M. et al. High-density polytetrafluoroethylene membranes in guided bone and tissue regeneration procedures: a literature review. Int. J. Oral Maxillofac. Surg., Philadelphia. v. 43, n. 1, p. 75-84, 2014.

31. RASMUSSON, L. et al. Effects of barrier membranes on bone resorption and implant stability in onlay bone grafts. An experimental study. Clin. Oral Implants Res., Copenhagen. v. 10, n. 4, p. 267-277, 1999.

32. STARCH-JENSEN, T. et al. Maxillary Sinus Floor Augmentation With or Without Barrier Membrane Coverage of the Lateral Window: a Systematic Review and Meta-Analysis. Oral Maxillofac. Res., [s.I], v. 10, n. 4, 2019.

33. LUNDGREN, A. K.; LUNDGREN, D.; TAYLOR, A. Influence of barrier occlusiveness on guided bone augmentation. An experimental study in the rat. Clin. Oral Implants Res., Copenhagen. v. 9, n. 4, p. 251-260, 1998.

34. DAHLIN, C. et al. Histological morphology of the e-FTFE/tissue interface in humans subjected to guided bone regeneration in conjunction with oral implant treatment. Clin. Oral Implants Res., Copenhagen. v. 9, n. 2, p. 100-106, 1998.

35. DONOS, N.; KOSTOPOULOS, L.; KARRING, T. Alveolar ridge augmentation by combining autogenous mandibular bone grafts and non-resorbable membranes: An experimental study in the rat. Clin. Oral Implants Res., Copenhagen. v. 13, n. 2, p. 185-191, 2002.

36. DE SANCTIS, M.; ZUCCHELLI, G.; CLAUSER, C. Bacterial colonization of barrier material and periodontal regeneration. J. Clin. Periodontol., Copenhagen. v. 23, n. 11, p. 1039-1046, 1996.

37. NOWZARI, H.; SLOTS, J. Microbiologic and clinical study of polytetrafluoroethylene membranes for guided bone regeneration around implants. Int. J. Maxillofac. Implants, Lombard, v. 10, n. 1, 1995.

38. FRIEDMANN, A. et al. Observations on a new collagen barrier membrane in 16 consecutively treated patients. Clinical and histological findings. J. Periodontol. Indianapolis. v. 72, n. 11, p. 1616-1623, 2001.

39. OHAYON, L. et al. Bone graft displacement after maxillary sinus floor augmentation with or without covering barrier membrane: a retrospective computed tomographic image evaluation. Int. J. Oral Maxillofac. Implants, Chicago. v. 34, n. 3, 2019.

40. JUNG, R. E. et al. Long-term outcome of implants placed with guided bone regeneration (GBR) using resorbable and non-resorbable membranes after 12-14 years. Clin. Oral Implants Res., Copenhagen. v. 24, n. 10, p. 1065-1073, 2013.

Submetido em: $15 / 04 / 2020$

Aceito em: $15 / 10 / 2020$ 